\title{
Numerical study of mixed convection heat transfer in a lid-driven cavity filled with a nanofluid
}

\author{
Abdelkader Boutra, Karim Ragui and Youb Khaled Benkahla \\ Laboratoire des Phénomènes de Transfert, Faculté de Génie Mécanique et de Génie des Procédés, Université des Sciences \\ et de la Technologie Houari Boumediene, BP 32 El Alia, 16111 Bab Ezzouar, Algiers, Algeria
}

Received 28 April 2014, Accepted 14 December 2014

\begin{abstract}
This paper reports a numerical study of mixed convection in a square enclosure, filled with a mixture of water and different types of nanoparticles. The upper and the bottom walls of the cavity are thermally insulated, while the remaining walls are mobile and differentially heated. In order to solve the general coupled equations, a computer code based on the finite volume method is used and it has been validated after a comparison between the present results and those of the literature. To make clear the effects of the governing parameters on the fluid flow and heat transfer inside the square, a wide range of the Richardson number, taken as 0.01 to 100, and the nanoparticles volume fraction, taken from 0 to $10 \%$, is investigated. The phenomenon is analyzed through streamlines and isotherm plots with a special attention to the Nusselt number. The obtained results show that the mean Nusselt number is an increasing function of the decrease Richardson number, and increases with increasing values of the nanoparticles volume fraction, and far from the natural convection mode, higher heat transfer is noted with Ag-water nanofluid. At the end, useful correlations predicting heat transfer rate as a function of the solid volume fraction are proposed for each value of the Richardson number, which predict the numerical results within $\pm 0.02 \%$.
\end{abstract}

Key words: Mixed convection / lid-driven cavity / Cu (or Ag) nanoparticles / water base fluid / finite volume method / optimal heat transfer

\section{Introduction}

Heat convection of nanofluids, which are a mixture of nanoparticles in a base fluid such as water and oil, has been recently an active field of research since they are used to improve heat transfer. Compared to other techniques for enhancing heat transfer in practical applications, nanofluids have the advantage of behaving like pure fluids because of the nanometric size of introduced solid particles. Thus, they are used as heat transfer fluids for various applications, such as advanced nuclear systems or micro/mini channel heat sinks, electronic equipment such power transistors, printed wiring boards and chip packages mounted on computer mother boards.

To reveal the effects of such added nanoparticles on the heat transfer, some papers dealing with natural convection of nanofluids, in differentially heated enclosures, were very helpful [1-4]. A review of the literature indicates that most researches [5-8] were achieved using a closed configuration whilst a little attention has been devoted

\footnotetext{
${ }^{a}$ Corresponding author: ragui-karim@live.fr
}

to the convection phenomenon within a moving wall enclosure $[9,10]$.

As such, the aim of the present paper is to examine the combined natural-forced convection heat transfer within this kind of cavities, filled with a nanofluid to predict, finally, the effects of the governing parameters such the Richardson number and the nanoparticles volume fraction on the fluid motion and heat transfer as well.

Referred to papers of Elif [11], Santra et al. [12] and many others $[13,14]$, the nanoparticles with a higher thermal conductivity (such as $\mathrm{Ag}$ and $\mathrm{Cu}$ ) produce a greater enhancement in the rate of heat transfer. Then, the use of the latter, $\mathrm{Cu}$ (or $\mathrm{Ag}$ ), is considered in this investigation.

It is to note that this kind of configurations represents an important industrial application such the shear mixture, where we train the fluid on both sides to generate a mixture.

\section{Problem statement}

The physical model of our problem, along with its boundary condition, is shown in Figure 1. A square cavity 


\section{Nomenclature}

\begin{tabular}{|c|c|}
\hline$\overline{C_{p}}$ & Specific heat transfer at a constant pressure $\left({\left.\mathrm{J} . \mathrm{kg}^{-1} \cdot \mathrm{K}^{-1}\right)}\right)$ \\
\hline$g$ & Gravitational acceleration $\left(\mathrm{m} \cdot \mathrm{s}^{-2}\right)$ \\
\hline Gr & Grashof number, $=g \beta \rho_{f}^{2} \Delta T H^{3} / \mu_{f}^{2}$ \\
\hline$H$ & Cavity height $(\mathrm{m})$ \\
\hline$k$ & Fluid thermal conductivity $\left(\mathrm{W} \cdot \mathrm{m}^{-1} \cdot \mathrm{K}^{-1}\right)$ \\
\hline$N u$ & Nusselt number \\
\hline$p^{*}$ & Pressure $(\mathrm{Pa})$ \\
\hline$P$ & Dimensionless pressure \\
\hline $\operatorname{Pr}$ & Prandtl number, $=C_{p} \mu_{\mathrm{f}} / k_{\mathrm{f}}$ \\
\hline$R e$ & Reynolds number, $=\rho_{\mathrm{f}} V_{\text {lid }} H / \mu_{\mathrm{f}}$ \\
\hline$R i$ & Richardson number, $=G r / R e^{2}$ \\
\hline$T$ & Dimensional temperature $(\mathrm{K})$ \\
\hline$u$ & Dimensional velocity component in $x$ direction $\left(\mathrm{m} . \mathrm{s}^{-1}\right)$ \\
\hline$U$ & Horizontal dimensionless component of velocity \\
\hline$v$ & Dimensional velocity component in $y$ direction $\left(\mathrm{m} . \mathrm{s}^{-1}\right)$ \\
\hline$V$ & Vertical dimensionless component of velocity \\
\hline$x$ & Horizontal coordinate $(\mathrm{m})$ \\
\hline$X$ & Dimensionless horizontal coordinate \\
\hline$y$ & Vertical coordinate $(\mathrm{m})$ \\
\hline$Y$ & Dimensionless vertical coordinate \\
\hline \multicolumn{2}{|r|}{$\begin{array}{l}\text { Greek symbols } \\
\end{array}$} \\
\hline $\bar{\beta}$ & Thermal expansion coefficient $\left(\mathrm{K}^{-1}\right)$ \\
\hline$\theta$ & Dimensionless temperature \\
\hline$\mu_{\mathrm{f}}$ & Fluid plastic viscosity $\left(\mathrm{kg} \cdot \mathrm{m}^{-1} \cdot \mathrm{s}^{-1}\right)$ \\
\hline$\rho_{\mathrm{f}}$ & Fluid density (kg.m $\left.{ }^{-3}\right)$ \\
\hline$\varphi$ & Nanoparticles volume fraction \\
\hline \multicolumn{2}{|r|}{$\begin{array}{l}\text { Subscript } \\
\end{array}$} \\
\hline avg & Average \\
\hline c & Cold \\
\hline $\mathrm{h}$ & Hot \\
\hline nf & Nanofluid \\
\hline $\mathrm{s}$ & Solid particles \\
\hline
\end{tabular}

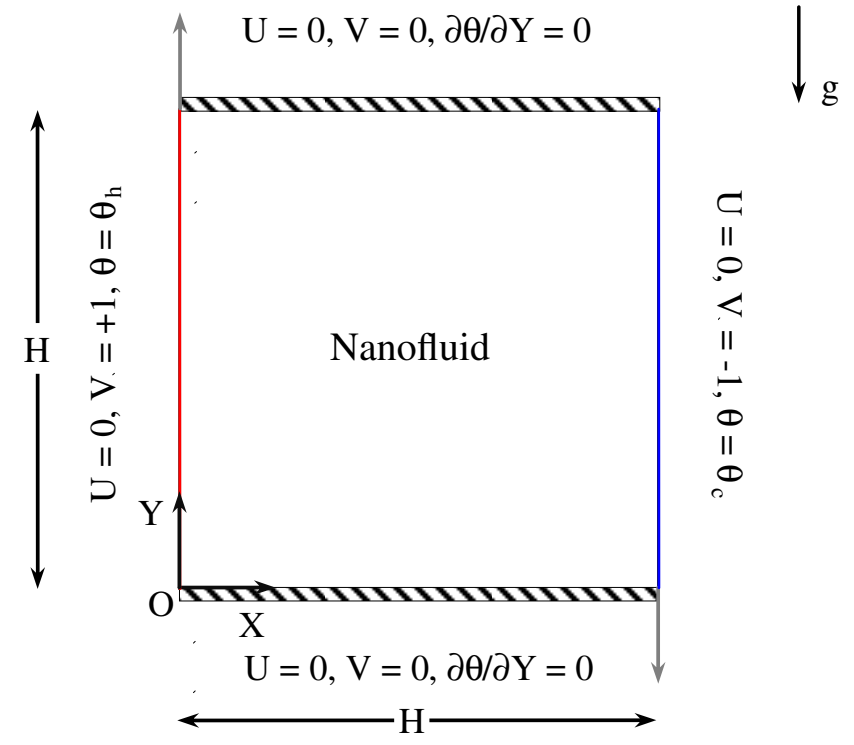

Fig. 1. Schematic view of the physical problem.

filled with a $\mathrm{Cu}$ (or Ag)-water nanofluid is considered such as the water and the $\mathrm{Cu}$ (or $\mathrm{Ag}$ ) nanoparticles are in
Table 1. Thermophysical properties of the base fluid and $\mathrm{Cu}$ (or Ag) nanoparticles.

\begin{tabular}{cccc}
\hline $\begin{array}{c}\text { Thermophysical } \\
\text { properties }\end{array}$ & $\begin{array}{c}\text { Base fluid } \\
\text { (water) }\end{array}$ & $\mathrm{Cu}$ & $\mathrm{Ag}$ \\
\hline$C_{\mathrm{p}}\left(\mathrm{J} \cdot \mathrm{kg}^{-1} \cdot \mathrm{K}^{-1}\right)$ & 4179 & 385 & 230 \\
$\rho\left(\mathrm{kg} \cdot \mathrm{m}^{-3}\right)$ & 997.1 & 8933 & 10500 \\
$k\left(\mathrm{~W} \cdot \mathrm{m}^{-1} \cdot \mathrm{K}^{-1}\right)$ & 0.613 & 401 & 418 \\
$\beta(\mathrm{K}) 10^{5}$ & 21 & 16.7 & 1.65 \\
\hline
\end{tabular}

thermal equilibrium. It is assumed that the temperature difference driving the convection comes from the vertical moving walls, when the horizontal walls are kept insulated. The flow and heat transfer are two-dimensional, steady and laminar. The Richardson number $\left(G r / R e^{2}\right)$ is taken as 0.01, 1 and 100 to simulate the forced, mixed and natural convection as well. The thermo-physical properties of the base fluid and the solid nanoparticles are given in Table 1. Constant thermo-physical properties are considered for the nanofluid, whereas the density variation in the buoyancy forces was determined using the Boussinesq approximation [15]. 


\section{Mathematical formulation}

The density, $\rho_{\mathrm{nf}}$, the heat capacity, $\left(\rho C_{p}\right)_{\mathrm{nf}}$, the thermal expansion coefficient, $(\rho \beta)_{\mathrm{nf}}$, and the thermal diffusivity of the nanofluide, $\alpha_{\mathrm{nf}}$, are defined, respectively, as follows [16]:

$$
\begin{aligned}
\rho_{\mathrm{nf}} & =(1-\varphi) \rho_{\mathrm{f}}+\varphi \rho_{\mathrm{s}} \\
\left(\rho C_{\mathrm{p}}\right)_{\mathrm{nf}} & =(1-\varphi)\left(\rho C_{\mathrm{p}}\right)_{\mathrm{f}}+\varphi\left(\rho C_{\mathrm{p}}\right)_{\mathrm{s}} \\
(\rho \beta)_{\mathrm{nf}} & =(1-\varphi)(\rho \beta)_{\mathrm{f}}+\varphi(\rho \beta)_{\mathrm{s}} \\
\alpha_{\mathrm{nf}} & =\frac{k_{\mathrm{nf}}}{\left(\rho C_{\mathrm{p}}\right)_{\mathrm{nf}}}
\end{aligned}
$$

The effective viscosity, $\mu_{\mathrm{nf}}$, and the thermal conductivity, $k_{\mathrm{nf}}$, of the nanofluid are determined according to the Brinkman [17], Equation (5), and Maxwell [18], Equation (6), models:

$$
\begin{aligned}
\mu_{\mathrm{nf}} & =\frac{\mu_{\mathrm{f}}}{(1-\varphi)^{2,5}} \\
\frac{k_{\mathrm{nf}}}{k_{\mathrm{f}}} & =\frac{\left(k_{\mathrm{s}}+2 k_{\mathrm{f}}\right)-2 \varphi\left(k_{\mathrm{s}}+k_{\mathrm{f}}\right)}{\left(k_{\mathrm{s}}+2 k_{f}\right)+\varphi\left(k_{\mathrm{s}}+k_{\mathrm{f}}\right)}
\end{aligned}
$$

The dimensionless continuity, momentum (according to horizontal and vertical directions) and energy equations are given, respectively, as:

$$
\begin{aligned}
\frac{\partial U}{\partial X}+\frac{\partial V}{\partial Y}= & 0 \\
U \frac{\partial U}{\partial X}+V \frac{\partial U}{\partial Y}= & -\frac{\partial P}{\partial X}+\frac{1}{R e} \frac{\mu_{\mathrm{nf}}}{\rho_{\mathrm{nf}} \nu_{\mathrm{f}}}\left[\frac{\partial^{2} U}{\partial X^{2}}+\frac{\partial^{2} U}{\partial Y^{2}}\right] \\
U \frac{\partial V}{\partial X}+V \frac{\partial V}{\partial Y}= & -\frac{\partial P}{\partial Y}+\frac{1}{R e} \frac{\mu_{\mathrm{nf}}}{\rho_{\mathrm{nf}} \nu_{\mathrm{f}}}\left[\frac{\partial^{2} V}{\partial X^{2}}+\frac{\partial^{2} V}{\partial Y^{2}}\right] \\
& +R i \frac{(\rho \beta)_{\mathrm{nf}}}{\rho_{\mathrm{nf}} \beta_{\mathrm{f}}} \theta \\
U \frac{\partial \theta}{\partial X}+V \frac{\partial \theta}{\partial Y}= & \frac{\alpha_{\mathrm{nf}}}{\alpha_{\mathrm{f}}} \frac{1}{\operatorname{Pr} \operatorname{Re}}\left[\frac{\partial^{2} \theta}{\partial X^{2}}+\frac{\partial^{2} \theta}{\partial Y^{2}}\right]
\end{aligned}
$$

where the non-dimensional variables introduced in Equations (7) to (10) are defined as:

$$
\begin{aligned}
& X=\frac{x}{H}, Y=\frac{y}{H}, U=\frac{u}{V_{\text {lid }}}, V=\frac{v}{V_{\text {lid }}}, \\
& P=\frac{p *}{\rho_{\text {nf }} V_{\text {lid }}^{2}}, \theta=\frac{T-T_{\mathrm{c}}}{T_{\mathrm{h}}-T_{\mathrm{c}}}
\end{aligned}
$$

The mean Nusselt number of the hot (or cold) wall is given by the following expressions:

$$
|N u|_{\text {wall }}=\left.\int_{0}^{1}\left(\frac{k_{\mathrm{nf}}}{k_{\mathrm{f}}}\right) \frac{\partial \theta}{\partial X}\right|_{X=0, H} \mathrm{~d} Y
$$

when the mean Nusselt number of the whole enclosure is calculated as:

$$
N u_{\mathrm{avg}}=\frac{N u_{\mathrm{h}}+N u_{\mathrm{c}}}{2}
$$

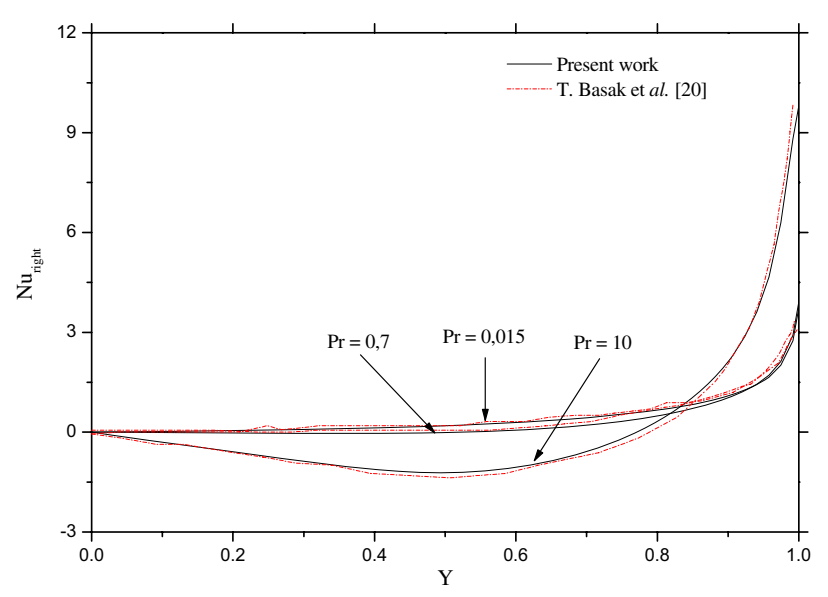

Fig. 2. Nusselt number evaluated at the right wall.

\section{Numerical procedure and validation}

The governing equations are discretized in space using the finite volume method, where the convection-diffusion terms are treated with a Power Law scheme. The resulting algebraic equations, with their associated boundary conditions, are then solved using the line by line method. As the momentum equation is formulated in terms of the primitive variables " $U, V$ and $P$ ", the iterative procedure includes a pressure correction calculation method, namely SIMPLER [19], to solve the pressure-velocity coupling. The adopted convergence criterion for the temperature, pressure, and velocity is given as:

$$
\text { Residual }=\frac{\sum_{j=1}^{m} \sum_{i=1}^{n}\left|\phi_{i, j}^{\xi+1}-\phi_{i, j}^{\xi}\right|}{\sum_{j=1}^{m} \sum_{i=1}^{n}\left|\phi_{i, j}^{\xi+1}\right|} \leqslant 10^{-6}
$$

$m$ and $n$ are the numbers of grid points in the $X$ - and $Y$-directions, respectively, $\varphi$ is any of the computed field variables and $\xi$ is the iteration number.

The computer code that we elaborated has been validated after a comparison between our results and those of Oztop and Abu-Nada [14] and Basak et al. [20] as shown in Table 2 and Figure 2, respectively. As it can be seen, the present results and those reported by Oztop and AbuNada [14] and Basak et al. [20] are in excellent agreement since the maximum gap is about $2 \%$.

Then, in order to determine a proper grid for the numerical simulations, a grid independence study is conducted for each value of Richardson number $(0.01,1$ and 100) as shown in Table 3 . The calculations are performed for $\mathrm{Cu}$-water nanofluid of $\varphi$ equals 0.02 with six different uniform grids: $51^{2}, 71^{2}, 91^{2}, 101^{2}, 110^{2}$, and $120^{2}$. As observed, a $101^{2}$ uniform grid is sufficiently fine to capture the temperature in the boundary layers adjacent to the moving walls. Hence, the latter can be employed to perform the subsequent numerical calculations. 
Table 2. Average Nusselt number of the heat source, comparison with Oztop and Abu-Nada [14] for the partially heated square cavity filled with $\mathrm{Cu}$-water nanofluid.

\begin{tabular}{cccc}
\hline Ra & $\varphi$ & $\begin{array}{c}\text { Oztop and } \\
\text { Abu-Nada [14] }\end{array}$ & Present work \\
\hline \multirow{4}{*}{$10^{3}$} & 0.00 & 1.004 & 1.005 \\
& 0.05 & 1.122 & 1.128 \\
& 0.10 & 1.251 & 1.248 \\
& 0.15 & 1.423 & 1.419 \\
& 0.20 & 1.627 & 1.621 \\
\hline \multirow{4}{*}{$10^{4}$} & 0.00 & 2.010 & 2.032 \\
& 0.05 & 2.122 & 2.115 \\
& 0.10 & 2.203 & 2.199 \\
& 0.15 & 2.283 & 2.291 \\
& 0.20 & 2.363 & 2.382 \\
\hline \multirow{4}{*}{$10^{5}$} & 0.00 & 3.983 & 3.992 \\
& 0.05 & 4.271 & 4.266 \\
& 0.10 & 4.440 & 4.429 \\
& 0.15 & 4.662 & 4.670 \\
& 0.20 & 4.875 & 4.861 \\
\hline \multirow{6}{*}{} & & &
\end{tabular}

Table 3. Average Nusselt number of the $\mathrm{Cu}$-water nanofluid in the square cavity for different uniform grids. $\varphi=0.02$ and $\operatorname{Pr}=6.2$.

\begin{tabular}{cccc}
\hline \multirow{2}{*}{ Nodes number } & \multicolumn{3}{c}{$N u_{\text {avg }}$} \\
\cline { 2 - 4 } & $R i=0.01$ & $R i=1$ & $R i=100$ \\
\hline $51 \times 51$ & 36.3109 & 16.0545 & 5.6052 \\
$71 \times 71$ & 43.7220 & 17.4163 & 5.8391 \\
$91 \times 91$ & 49.9145 & 17.9306 & 5.9436 \\
$101 \times 101$ & 53.1219 & 19.9059 & 6.2693 \\
$110 \times 110$ & 53.1286 & 19.9093 & 6.2697 \\
$120 \times 120$ & 53.1369 & 19.9170 & 6.2695 \\
\hline
\end{tabular}

\section{Results and discussion}

\subsection{Effect of Richardson number and solid volume fraction}

First of all, the Richardson number is adjusted between 0.01 and 100, when the nanofluid volume fraction is fixed at 0.02 . The streamlines and the isotherm patterns for various values of the Richardson number are presented in Figure 3. In general, a typical single-cell flow structure is formed inside the enclosure. By increasing the Richardson number, the natural convection effect on the nanofluid flow is found dominated.

Regarding the isotherms, the thin thermal boundary layers formed along the side moving walls of the square are an indication of large temperature gradients along these surfaces. By increasing the Richardson number, these thermal boundary layers become thicker and then, the isotherms get a horizontal distribution inside the enclosure.

The effect of the nanoparticles volume fraction is also investigated. As displayed in Figure 4, it can be seen that the increase in the nanoparticles volume fraction decreases the thickness of the thermal boundary layers to be more compact nearer the active walls.
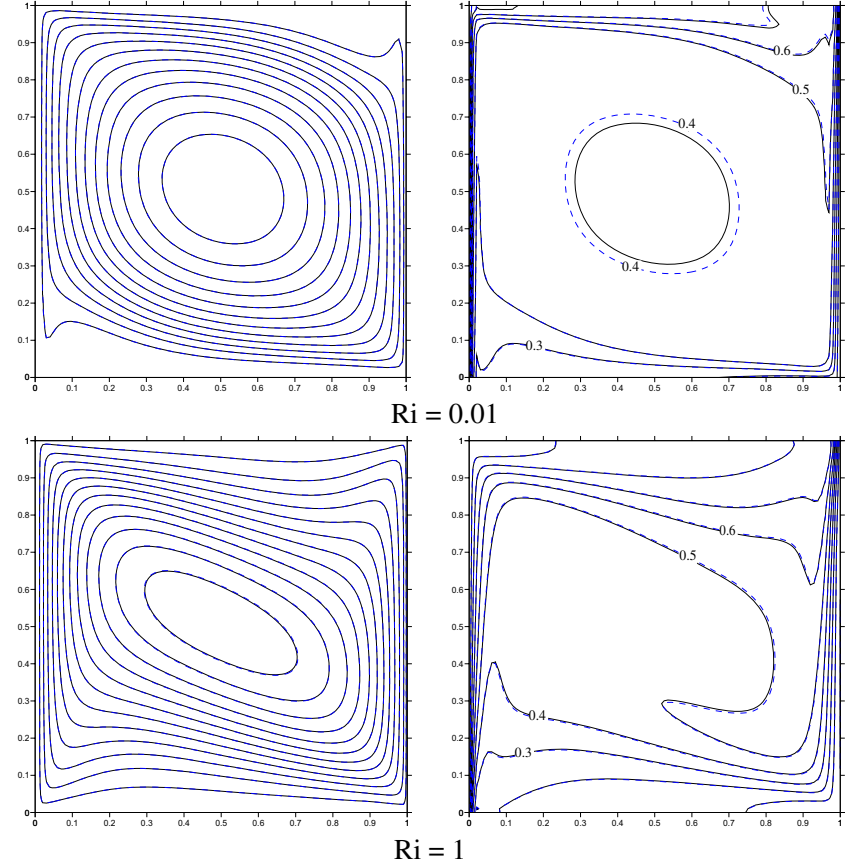

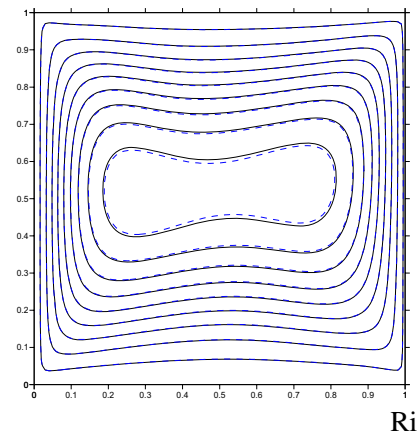

(a)

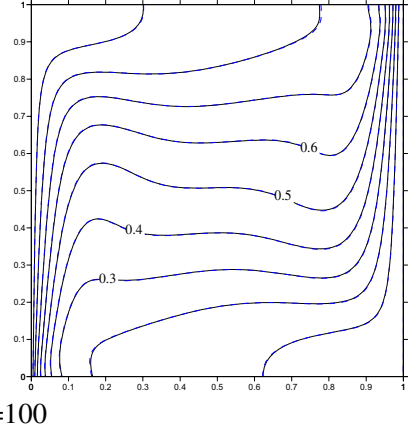

(b)
Fig. 3. Streamlines (a) and Isotherm plots (b) for different values of the Richardson number. $\varphi=0.02,[-\mathrm{Cu}$-water - - Ag-water].

\subsection{Nusselt number correlations}

The variation of the mean Nusselt number as a function of $\mathrm{Cu}$ and $\mathrm{Ag}$ nanoparticles volume fraction, for different values of the Richardson number, is shown in Figure 5. For both nanofluid cases, it can be seen that the mean Nusselt number is a linear increasing function of the nanoparticles volume fraction, and decreases by increasing the Richardson number. Besides, far from the natural convection mode, higher heat transfer is noted with the Ag-water nanofluid compared to the $\mathrm{Cu}$-water nanofluid.

Figure 6 shows the ratio $N u^{*}$, which defined as $N u_{\text {avg }(\varphi \neq 0)} / N u_{\text {avg }(\varphi=0)}$, as a function of the Ag-water nanofluid volume fraction for each value of the Richardson number. Summarizing the numerical results, predictive correlations relating $N u^{*}$ to $\varphi$ can be proposed in the form:

$$
N u^{*}=1+A_{\mathrm{Ri}} \varphi
$$

where the coefficient $A_{\mathrm{Ri}}$ of each Richardson number is listed in Table 4 along with the minimum $R^{2}$ value to 

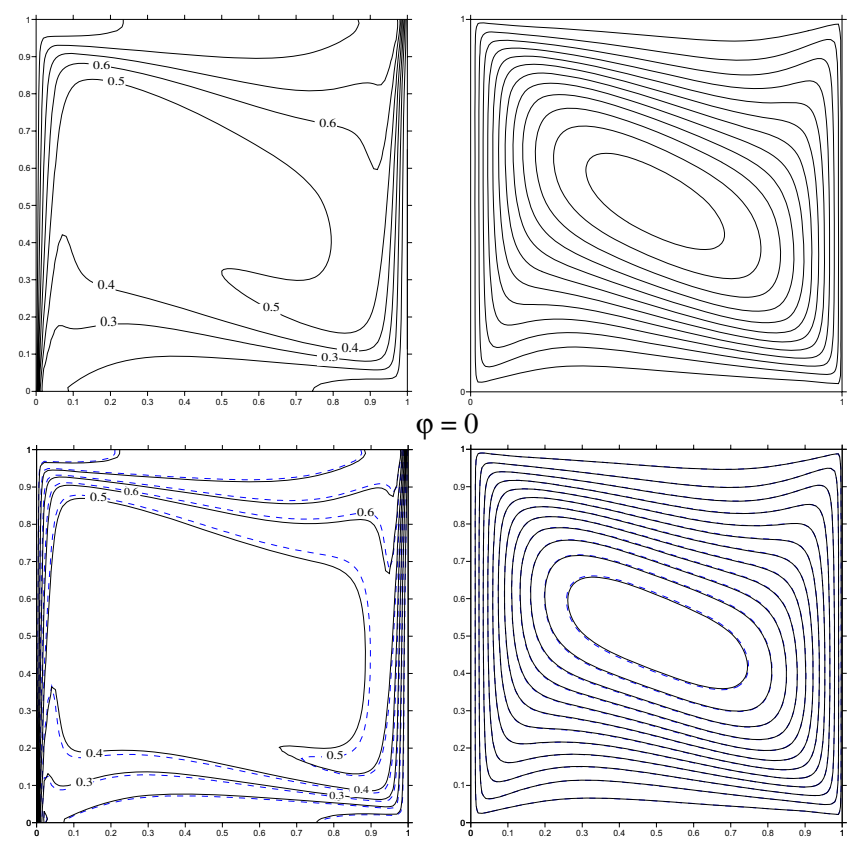

(a)

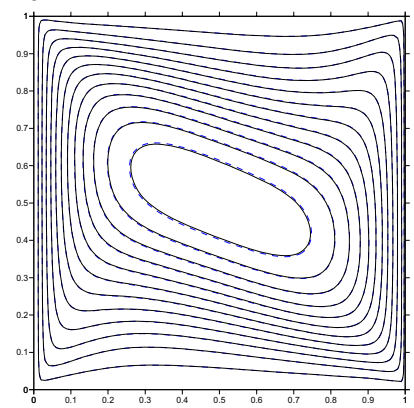

$\varphi=0.10$

(b)

Fig. 4. Streamlines (a) and Isotherm plots (b) of the nanofluids for different values of the solid volume fraction. $R i=1$. [- $\mathrm{Cu}$-water, - - - Ag-water].

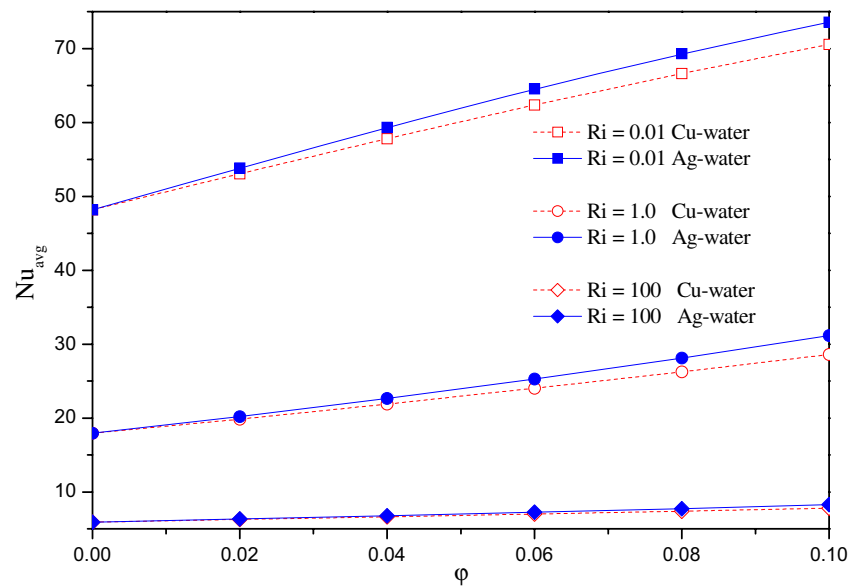

Fig. 5. Variation of the mean Nusselt number with the nanoparticles volume fraction for different values of the Richardson number.

Table 4. Curve-fit constant values of Equation (15).

\begin{tabular}{cccc}
\hline$A_{R i=0.01}$ & $A_{R i=1}$ & $A_{R i=100}$ & $R^{2}$ \\
\hline 7.380 & 5.497 & 4.002 & 0.998 \\
\hline
\end{tabular}

indicate the goodness of the curve-fit employed in Figure 6 . These correlations are found to predict the numerical results within $\pm 0.02 \%$.

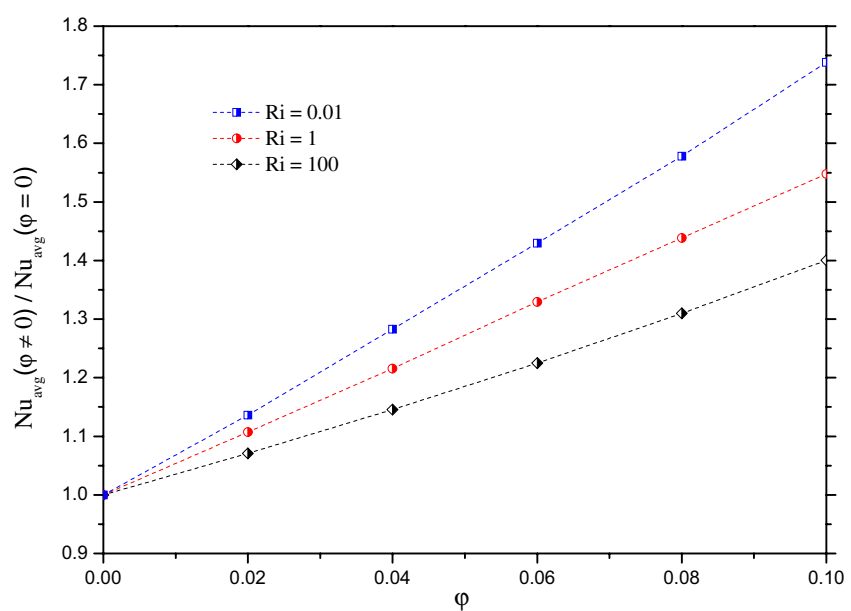

Fig. 6. Heat enhancement parameter $N u^{*}$ with $\varphi$ for different values of the Richardson number.

\section{Conclusion}

Through our paper, a numerical investigation has been performed to make clear effect of using different nanofluids on mixed convection phenomenon inside a square, moving walls, enclosure. The obtained results may resume as follows:

- The heat transfer acts as a decreasing function with the increase Richardson number.

- The heat transfer enhancement consequent to the dispersion of solid nanoparticles into the base fluid increases by increasing the nanoparticles volume fraction.

- The type of the nanoparticles is a key factor for heat transfer enhancement. The highest values are obtained using Ag nanoparticles.

- Useful correlations predicting the heat transfer rate as a function of the solid volume fraction can be proposed for each value of the Richardson number, which predict the numerical results within $\pm 0.02 \%$.

\section{References}

[1] S.U.S. Choi, Enhancing thermal conductivity of fluids with nanoparticles, ASME Fluids Eng. Division 231 (1995) 99-105

[2] X. Wang, X. Xu, S.U.S. Choi, Thermal Conductivity of Nanoparticle-Fluid Mixture, J. Thermophys. Heat Transfer 13-4 (1999) 474-480

[3] R.Y. Jou, S.C. Tzeng, Numerical research of nature convective heat transfer enhancement filled with nanofluids in rectangular enclosures, Int. Commun. Heat Mass Transfer 33 (2006) 727-736

[4] A.K. Santra, S. Sen, N. Chakraborty, Study of heat transfer augmentation in a differentially heated square cavity using copper-water nanofluid, Int. J. Thermal Sci. 47 (2008) 1113-1122

[5] Y. He, Y. Men, Y. Zhao, H. Lu, Y. Ding, Numerical investigation into the convective heat transfer of $\mathrm{TiO}_{2}$ nanofluids flowing through a straight tube under the laminar flow conditions, Appl. Thermal Eng. 29 (2009) 1965-1972 
[6] H.R. Ashorynejad, A.A. Mohamad, M. Sheikholeslami, Magnetic field effects on natural convection flow of a nanofluid in a horizontal cylindrical annulus using lattice Boltzmann method, Int. J. Thermal Sci. 64 (2013) 240-250

[7] A. Akbarinia, A. Behzadmehr, Numerical study of laminar mixed convection of a nanofluid in horizontal curved tubes, Appl. Thermal Eng. 27 (2007) 1327-1337

[8] A. Abouei Mehrizi, M. Farhadi, S. Shayamehr, Natural convection flow of $\mathrm{Cu}$-Water nanofluid in horizontal cylindrical annuli with 2 inner triangular cylinder using lattice Boltzmann method, Int. Commun. Heat Mass Transfer (2013) 977-987

[9] A. Arani , S. Mazrouei, M. Mahmoodi, A. Ardeshiri, M. Aliakbari, Numerical study of mixed convection flow in a lid-driven cavity with sinusoidal heating on side walls using nanofluid, Superlattices Microstructures 51 (2012) 893-911

[10] B. Ghasemi, S.M. Aminossadati, Mixed convection in a lid-driven triangular enclosure filled with nanofluids, Int. Commun. Heat Mass Transfer 37 (2010) 1142-1148

[11] B.O. Elif, Natural convection of water-based nanofluids in an inclined enclosure with a heat source, Int. J. Thermal Sci. 48 (2009) 2063-2073

[12] A.K. Santra, S. Sen, N. Chakraborty, Study of heat transfer augmentation in a differentially heated square cavity using copper-water nanofluid, Int. J. Thermal Sci. 47 (2008) 1113-1122
[13] B. Ghasemi, S.M. Aminossadati, Natural convection heat transfer in an inclined enclosure filled with a $\mathrm{CuO}$-water nanofluid, Numer. Heat Transfer, Part A Appl. (2009) 807-823

[14] H.F. Oztop, E. Abu-Nada, Numerical study of natural convection in partially heated rectangular enclosures filled with nanofluids, Int. J. Heat Fluid Flow 29 (2008) 1326-1336

[15] A. Bejan, Convection heat transfer, John Wiley \& Sons, Inc., Hoboken, New jersey, USA, 2004

[16] K. Khanafer, K. Vafai, M. Lightstone, Buoyancy-driven heat transfer enhancement in a two-dimensional enclosure utilizing nanofluid, Int. J. Heat Mass Transfer 46 (2003) 3639-3653

[17] H.C. Brinkman, The viscosity of concentrated suspensions and solution, J. Chem. Phys. 20 (1952) 571-581

[18] J.C. Maxwell-Garnett, A Treatise on Electricity and Magnetism, Oxford University Press, Cambridge, UK, 1873, vol. II, p. 54

[19] S.V. Patankar, Numerical Heat transfer and fluid flow, Hemisphere Publishing Corporating, Taylor and Francis Group, New York, 1980

[20] T. Basak, S. Roy, P.K. Sharma I. Pop, Analysis of mixed convection flows within a square cavity with uniform and non-uniform heating of bottom wall, Int. J. Thermal Sci. 48 (2009) 891-912 